\title{
韩布兴: 尽心、尽力、尽责
}

智欣

《中国科学》杂志社, 北京 100717

zhixin@scichina.org

\section{Buxing Han: Enthusiasm, dedication and mission}

\section{Xin Zhi}

Science China Press, Beijing 100717, China zhixin@scichina.org

doi: 10.1360/TB-2021-0143

韩布兴, 中国科学院化学研究所研究员、博士生导师、 中国科学院院士、发展中国家科学院院士、英国皇家化学 会会士, 主要从事物理化学与绿色化学的交叉研究. 2008年 至今担任《中国科学: 化学》编委, 2008 2014年担任《科学 通报》编委，2014年至今担任《科学通报》(中文版)副主编. 2020 年是 《中国科学》和《科学通报》(简称“两刊”)创刊70 周年, 《中国科学》杂志社专访韩布兴院士, 请他分享在“两 刊”的工作体会.

您在“两刊”发表的第一篇文章是什么? 发表经过如何?

韩布兴: 1997年, 我在《科学通报》发表了文章“ $\mathrm{CO}_{2}$-正 丁醇、 $\mathrm{CO}_{2}$-二甲基亚砜混合超临界流体中水杨酸的氢键缔 合”, 这是我在“两刊”发表的第一篇论文. 我们从氢键缔合的 角度解释了为什么少量共溶剂可以大幅度提高超临界流体 溶解溶质的能力, 我认为这是我1991年回国后的最好工作之 一. 我还在上大学时就知道《科学通报》是一本具有重要影 响、高水平的期刊, 发表了许多十分重要的成果. 因此, 我们 一致决定将这个重要结果投到《科学通报》, 最终顺利接受 发表. 此后, 我也经常鼓励课题组的同仁们将好的成果投给 “两刊”. 我们课题组陆续在“两刊”发表研究性论文和评述性 文章30余篇, “两刊”提供的高端学术展示平台, 伴随着我一 路前行.

您多年担任“两刊”副主编和编委，您怎样看待“两刊”的 发展?

韩布兴: “两刊”自创刊至今已有70年的历史，曾经走过 辉煌的岁月, 发表过很多里程碑式的科学成果. 从1950年 《科学通报》(中文版)、《中国科学》(中文版) 2 本期刊创刊

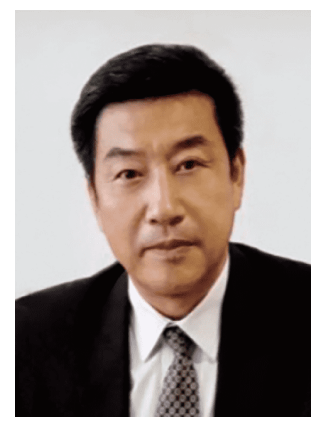

韩布兴 院士

至今, 目前已经发展成为涵盖多学科领域的期刊集群, 包括 《中国科学》系列和《科学通报》中英文17种期刊. 尽管发 展道路曲折, 但经过几代人的努力, “两刊”已取得了长足的发 展, 为科学技术的进步作出了重要贡献，为服务国家科技创 新发挥了重要作用. 与其他国内期刊相比，“两刊”现阶段仍 然有自己的优势. 毫无疑问, 随着我国科技影响力在国际上 的不断提升，相信通过我们的共同努力，“两刊”的发展会更 快更好, 影响力会继续快速增加, 最终将实现成为世界一流 科技期刊的目标.

2014年起, 您担任《科学通报》(中文版)副主编, 在推动 期刊发展方面您采取的主要措施是什么?

韩布兴: 2014年，“两刊”理事会决定《科学通报》中英 文版分开办刊，并决定分别设立新一届中文版和英文版编委 会, 两个版本各自独立, 不再对照出版, 以此来推动两个版本 各自更好的发展. 我很荣幸担任了《科学通报》中文版首任 
化学学科副主编, 主持化学学科工作. 诚然, 分开办刊给两本 期刊都带来了新的发展机遇, 但是中文刊想要实现新的突破 非常难, 我深感肩上的担子很重.

令人欣慰的是, 我们组建的化学编委会委员甘于奉献、 勇于担当. 在遴选编委时, 我们一方面考虑他们的学术权威 性和学科领域分布, 另一方面考虑他们是否有办好中文刊的 热情. 在充分了解、沟通交流后，我们达成了如下的办刊理 念: 中文科技期刊在推动科技发展、传播中华科技文化中有 着不可替代的作用, 要保护和提高中文期刊的学术地位, 要 有办好中文科技期刊的“文化自信”. 统一思想, 凝聚力量, 编 委会老师专业、务实的工作作风，夯实了《科学通报》中文 旗舰期刊的地位.

分刊初期, 受当时国内科研评价体系的影响, 科研成果 更倾向于发表在英文期刊上，中文期刊稿源短缺现象很严重. 编委在2015 2017年期间组织出版了13个学科前沿领域的专 题(辑), 这一方面增加了期刊稿源、提高了学术质量; 另一方 面通过集中宣传，扩大了文章和期刊的可见度. 经过几年的 发展，广大科研工作者对期刊有了重新认识和认可，也逐渐 意识到中文科技期刊的重要性. 近几年，编委积极宣传期 刊、严把学术质量、创新栏目建设, 这些卓有成效的工作, 推动了期刊更好更快的发展. 在这里也要感谢编辑部同仁的 努力、奋斗, 这是一个志同道合、团结协作的团队，大家勇 于担当、甘于奉献、团结协作、精益求精.

近年, 《科学通报》出版了几期绿色化学主题的专题 (辑), 您是基于什么考虑推动组织了它们的出版?

韩布兴: 碳是地球上的重要元素, 我们的衣、食、住、 行都离不开碳, 碳资源在人类文明进程中发挥着重要作用. 随着人类社会的发展，煤、石油、天然气等化石碳资源日趋 枯竭，二氧化碳的大量排放导致碳循环严重失衡，经济、资 源、环境三者间的矛盾日益突出. 基于绿色环保和可持续发 展的考量, 绿色化学应运而生, 成为了 21 世纪最重要的主题之 一, 是化学创新和发展的重要方向, 与可持续发展的多个方面 直接相关, 并为可持续发展提供科学基础和技术保障.

绿色化学在基础研究和工业应用等方面均取得许多重 要进展, 但还远未达到可持续发展的要求, 绿色化学研究任 重而道远. 我国在绿色化学研究方面起步较早, 在绿色化学 概念提出后不久就开始了相关研究，中国学术界、企业界和
政府均对绿色化学领域高度重视. 绿色化学是具有明确社会 需求和科学目标的新兴交叉学科, 作为自然科学领域的综合 性期刊, 《科学通报》应该努力推动绿色化学研究和发展 我于 2015 年组织“绿色溶剂体系性质及应用研究”专辑, 同年 邀请中科院化学所刘志敏编委组织出版了 “绿色碳科学”专 辑, 迄今为止这两个专辑文章在中国知网已有约 2 万次的下 载, 有效促进和推动了学术交流和领域发展. 二氧化碳是主 要的温室气体, 也是无毒、丰富、便宜易得的可再生碳资源, 把它转化成重要的化学品、材料、能源产品具有重要意义. 我国学者在二氧化碳化学领域取得了很多国际先进水平成 果，为了集中展现我国学者的相关研究成果，发挥我国在有 机化学、精准合成、催化科学、绿色介质以及高分子合成 等研究领域的综合优势, 推动二氧化碳化学转化研究, 2020 年我邀请何良年编委组织出版了两期“面向可持续发展的二 氧化碳化学”专题.

您对青年科研工作者有哪些期望或寄语?

韩布兴: 青年科研工作者应努力发挥自身的创造和创新 能力. 创新是推动社会进步的根本动力. 青年时期是创造和 创新能力的顶峰时期, 很多重大科技成果是科学家在年轻时 候取得的. 因此应在青年时期努力培养和发挥创造和创新能 力. 青年科研工作者应该有远大的理想, 勇攀科技高峰, 积极 应对人类面临的重大挑战，不仅要考虑自己可以做什么，更 要考虑自己应该做什么, 社会需要什么.

青年科研工作者应具备以下一些优秀品质. 其一, 努力 工作是优秀科研人员必备的条件. 要想取得重大创新成果, 必须付出比常人更多的时间和精力. 其二，要始终保持怀疑 和批判精神, 大胆假设、小心求证. 其三, 不仅要关注自己科 学领域的发展, 还应关注其他相关领域的进展, 不断努力借 鉴各个领域的科研成果和科学方法. 当今很多重大科技难题 往往涉及多方面的问题, 一个人的知识面和能力总是有限的, 良好的团队合作精神对于取得重大成果很重要. 年轻科学家 也应该与年长科学家多交流, 吸取经验.

在这里我还要鼓励青年学者积极参与科技期刊工作. 科 技期刊在学术圈的影响力会为青年学者施展才华和脱颖而 出创造条件，同时期刊搭建的沟通交流平台，也会助力青年 学者进步与成长. 欢迎青年学者参与“两刊”的建设，积极投 稿、审稿, 为期刊发展献计献策. 